\title{
LOURENÇO FILHO E O MODERNO ENSINO DE ARITMÉTICA: PRODUÇÃO E CIRCULAÇÃO DE UM MODELO PEDAGÓGICO
}

\author{
Wagner Rodrigues Valente \\ Universidade Federal de São Paulo, Brasil.
}

Resumo

O texto analisa a produção e a circulação de material utilizado para o ensino de Aritmética que ficou conhecido com o nome de Cartas, Mapas ou Quadros de Parker. O material teve circulação durante toda a primeira metade do século 20. A análise realizada mostra o papel de Lourenço Filho na longa permanência deste dispositivo de ensino, transformado em ícone da pedagogia moderna da matemática na escola primária.

Palavras-chave: história da educação matemática, pedagogia intuitiva da aritmética, Lourenço Filho, Cartas de Parker.

\section{LOURENÇO FILHO AND MODERN TEACHING ARITHMETIC: PRODUCTION AND CIRCULATION OF A MODEL EDUCATIONAL}

\begin{abstract}
The text examines the production and circulation of material used for teaching arithmetic which became known by the name of Tables, Maps and Charts Parker. The material was outstanding during the entire first half of the twentieth century. The analysis shows the role of Lourenço Filho long stay in this teaching device, transformed into an icon of modern pedagogy of mathematics in primary school.

Key-words: history of mathematics education, object lessons of arithmetic, Lourenço Filho, Tables Parker.

\section{LOURENÇO FILHO Y LA FORMA MODERNA DE LA ENSEÑANZA DE ARITMÉTICA: PRODUCCIÓN Y DISTRIBUCIÓN DE UN MODELO EDUCATIVO}

Resumen

El texto tiene como objetivo analizar la producción y circulación de material utilizado para la enseñanza de la aritmética que se conoció con el nombre de tablas, mapas y gráficos Parker. El material fue excelente durante toda la primera mitad del siglo 20 . El análisis pone de manifiesto el papel de Lourenço Filho como responsable de la larga persistencia de este dispositivo de 
enseñanza, convertido en un icono de la pedagogía moderna de las matemáticas en la escuela primaria.

Palabras-clave: historia de la enseñanza de las matemáticas, pedagogía aritmética intuitiva, Lourenço Filho, Tablas Parker.

\section{LOURENÇO FILHO ET L'ENSEIGNEMENT MODERNE DU CALCUL: PRODUCTION ET DIFFUSION D'UN MODĖLE POUR L'EDUCATION MATHÉMATIQUE}

\section{Résumé}

Le texte vise à analyser la production et la circulation des matériaux utilisés pour l'enseignement de l'arithmétique qui est devenu connu sous le nom de Tables de Parker. Le matériau a été remarquable durant toute la première moitié du $20 \mathrm{e}$ siècle. L'analyse montre le rôle de Lourenço Filho comme responsable de la longue persistance de ce dispositif d'enseignement, transformé en une icône de la pédagogie moderne des mathématiques à l'école primaire.

Mots-clé: histoire de l'enseignement des mathématiques, pédagogie arithmétique intuitive, Lourenço Filho, Tables de Parker. 


\section{Considerações iniciais}

uito extensa é a produção de Manoel Bergström Lourenço Filho e a $M$ quantidade de referências bibliográficas sobre este educador. Livros, capítulos de livros, dissertações, teses e relatórios de pesquisas, artigos em periódicos, verbetes de dicionários, depoimentos, dentre muitos outros trabalhos foram inventariados na obra Por Lourenço Filho: uma biobibliografia, organizada por Carlos Monarcha e Ruy Lourenço Filho, com a colaboração de vários autores de história da educação brasileira. Foi possível aos pesquisadores inventariarem um total de 771 referências da produção intelectual de Lourenço Filho. Relativamente aos trabalhos sobre este autor, o número totalizado foi de 369 referências (Monarcha; Lourenço Filho, 2001).

Esta imensa produção, no entanto, não mostra a existência de textos que tenham analisado as propostas elaboradas por Lourenço Filho para ensino de Matemática, obras e materiais destinados aos primeiros anos escolares.

Em tempo recente, no âmbito das pesquisas sobre história da educação matemática, tratamos do tema em dois estudos. O primeiro deles constituiu capítulo da obra O curso de Lourenço Filho na Escola Normal do Ceará, intitulado A metodologia da aritmética nas anotações de aulas de Lourenço Filho, publicado em 2009 e organizado pelas historiadoras da educação Maria Helena Camara Bastos e Maria Juraci Maia Cavalcante. $O$ estudo analisou as anotações de alunas feitas nas aulas de Aritmética que tiveram com o educador paulista, em meados da década de 1920, em Fortaleza. Como síntese da análise realizada, chegamos à conclusão de que a metodologia da Aritmética professada por Lourenço Filho, àquela altura, constituiu uma orientação para o ensino intuitivo, com materiais pedagógicos a auxiliar a tentativa de ruptura com um dos pontoschave da cultura escolar do ler, escrever e contar: a centenária tradição de cantar de cor a tabuada (Valente, 2009, p. 205).

Posteriormente, um segundo estudo, que levou em conta o papel de Lourenço Filho na educação matemática, constituiu trabalho mais aprofundado sobre a formação matemática do professor primário em perspectiva histórica. O texto foi publicado em livro, com o título A matemática na formação do professor do ensino primário - São Paulo, 1875-1930. No capítulo final da obra abordamos o embate das representações intuitivas e escolanovistas para o ensino de Matemática nos primeiros anos escolares. Como resultado, concluiu-se que

em finais da década de 1920 as referências paulistas perdem força em âmbito nacional. Um novo tempo surge com o movimento da Escola Nova e sua difusão diferenciada pelos estados brasileiros. No entanto, em termos do ensino de matemática, mesmo o representante mais ativo do escolanovismo - Lourenço Filho - não conseguirá dar passo adiante na mudança do ideário das lições de coisas, para o que seria o método ativo da matemática. A formação matemática do professor primário continuará a ter discursos e propostas calcadas nas Cartas de Parker ainda por longa data. (Valente, 2011, p. 115)

A partir destes dois estudos muitas questões ainda ficaram para ser respondidas, bem como motivaram a necessidade de realizar um estudo mais acurado sobre a produção de Lourenço Filho em termos da educação matemática. Isto deu origem ao projeto Lourenço Filho e a matemática da escola nova, que conta com o apoio da Fapesp, 
subprojeto da pesquisa $A$ constituição dos saberes elementares matemáticos: a aritmética, a geometria e o desenho no curso primário em perspectiva históricocomparativa, 1890-1970.

Com o projeto Lourenço Filho e a matemática da escola nova já foi possível, mesmo que parcialmente, aprofundar o entendimento do papel deste educador em termos de suas propostas para o ensino de Aritmética no curso primário. Isso ensejou a elaboração de dois estudos divulgados em recentes congressos de História da Educação. No primeiro deles - $7^{\circ}$ Congresso Brasileiro de História da Educação - apresentamos a comunicação Lourenço Filho, as Cartas de Parker e as transformações da aritmética escolar.

O segundo - 36 ${ }^{a}$ Reunião Nacional da Anped - ensejou a elaboração do estudo intitulado Do ensino ativo para a escola ativa: Lourenço Filho e o material de Parker para a aritmética do curso primário. Os dois estudos permitiram apreender o significado das chamadas Cartas de Parker no ensino de Aritmética do curso primário e as ações do educador paulista. Os resultados obtidos por estes estudos anteriores são trazidos a este texto, agora para a compreensão da trajetória de conformação de um modelo pedagógico para o ensino de Matemática, que teve circulação por praticamente todo o Brasil, pelas Cartas de Parker. Assim, por este texto pretende-se responder à seguinte questão: como se constituiu e que fatores podem explicar a circulação do modelo pedagógico Cartas de Parker para o ensino de Aritmética no curso primário, por toda a primeira metade do século $20 ?$

\section{Cartas de Parker: a recepção e produção de um material didático para o ensino de Aritmética}

Em finais do século 19 difundem-se, internacionalmente, as Lições de coisas, forma pela qual é divulgado e popularizado o método intuitivo. As Lições remetem mais longinquamente aos estudos de Pestalozzi, na renovação da pedagogia, face ao ensino tido como tradicional: as coisas antes das palavras, a educação pelas coisas e não a educação pelas palavras. Sob esta perspectiva começam a proliferar materiais que objetivam as coisas e, em particular para a Matemática, buscam-se coisas que irão dar lições aritméticas. Talvez o material que melhor simbolize este tempo de chegada dos novos dispositivos didáticos, para o ensino de Aritmética nos anos iniciais, sejam as Cartas de Parker ${ }^{1}$.

As Cartas de Parker constituem um conjunto de gravuras cujo fim é o de auxiliar o professor a conduzir metodicamente o ensino, sobretudo, das quatro operações fundamentais. Junto de cada gravura há uma orientação ao professor de como deveria

\footnotetext{
1 Francis Wayland Parker (1837-1902), segundo Lawrence Cremin (1961), foi um dos pioneiros do progressive movement in american education. Segundo o mesmo autor, nos dizeres de John Dewey, Parker representa o "father of progressive education" (p. 129). Ainda de acordo com Cremin, em meio às suas atividades pedagógicas, Parker teve a oportunidade, com o recebimento de uma herança familiar, de viajar à Europa e tomar contato com o desenvolvimento teórico das pesquisas pedagógicas. Vistas as novidades dos trabalhos europeus, em matéria de ensino nas primeiras letras, resolveu financiar e promover ações similares nos EUA. Suas ideias e inovações curriculares fazeram sucesso, sobretudos a partir de 1883, quando Parker assumiu a direção da Escola Normal de Cook County, em Chicago. Neste novo ambiente formalizou as suas propostas pedagógicas a partir de elementos vindos de Pestalozzi, Froebel e Herbart (Montagutelli, 2000). Em 1883 publicou Talks on teaching e, em 1894, Talks on pedagogics. Este último livro Cremin (1961) considera como, possivelmente, o primeiro tratado norteamericano de pedagogia a ganhar renome internacional.
} 
dirigir-se à classe, de modo a fazer uso de cada uma delas e avançar no ensino da Aritmética ${ }^{2}$.

Desde o primeiro número da Revista de Ensino/São Paulo ${ }^{3}$ elas são editadas pelo periódico. As Cartas de Parker estão presentes na seção denominada Pedagogia prática, sob o título Cartas de Parker para o ensino de aritmética nas escolas primárias. Já nas páginas iniciais há a justificativa para a publicação do material:

Em vista dos magníficos resultados por nós colhidos com o emprego das Cartas de Parker, no ensino de aritmética em nossas escolas, e não haver à venda, no mercado, julgamos prestar um relevante serviço aos colegas dedicados e a seus alunos, publicando-as na nossa Revista. Cada carta que vai acompanhada da respectiva explicação em português; poderá ser copiada pelo professor no quadro negro, à medida que dela for precisando, trabalho este que não lhe tomará mais que 5 minutos de tempo, e que será compensado com usura. (1902, p. 35)

Segue ao anúncio a publicação das Cartas de números 1 ao 10 . Posteriormente, noutros números da revista, saem as demais. Assina a matéria, J. B. que, em números posteriores identifica-se como Joaquim Brito. Por certo, trata-se de Joaquim Luiz de Brito, normalista formado em 1882, membro da diretoria da Associação Beneficente do Professorado Público de São Paulo e redator efetivo da Revista de Ensino (Panizzolo, 2006).

Organizado e técnico, o material de Parker possibilita submeter o ensino a uma sequência programada de perguntas do professor, à espera de respostas dos alunos para avançar na leitura de cada uma das Cartas. Porém, isso não está posto de modo linear, previsível e repetitivo. As ações pedagógicas, as interações professor e alunos, com o material, devem ter outro caráter. Diferentemente da prática consagrada de decorar tabuada, quando está presente a repetição e a previsão das etapas seguintes com o dois e um, três, dois e dois, quatro, dois e três, cinco ou, ainda, do dois vezes um, dois, dois vezes dois, quatro etc., numa dinâmica de cantar a tabuada escrita na lousa e repetida pela classe ao sinal do professor, as Cartas trazem outra organização didáticopedagógica. Cada uma delas tem uma forma própria com objetivos definidos para o ensino e aprendizagem.

Joaquim Luiz de Brito, professor que assinou os artigos da Revista de Ensino que divulgam as Cartas de Parker, teve papel importante na oficialização deste material didático para as escolas paulistas. Junto com João Lourenço Rodrigues e Antônio

\footnotetext{
${ }^{2}$ A pesquisa de David Antonio da Costa mostra que, possivelmente, Parker apropriou-se do Método Grube na confecção de suas Cartas. O método leva o nome de autor alemão que, em 1842, publicou, em Berlim, o livro Leitfaden für das Rechnen in der Elementarschule nach den Grundsätzen einer heuristischen Methode (Guia para o cálculo nas classes elementares, seguindo os princípios de um método heurístico). O Método Grube, em síntese, consiste em levar os alunos por si mesmos, e de modo intuitivo, a realizarem as operações fundamentais do cálculo elementar (Costa, 2010, p. 119). A possibilidade de Parker ter elaborado seus materiais a partir do trabalho de August Wilhelm Grube é corroborada por Seeley (1970), que revela ter o Método Grube exercido muita influência nos Estados Unidos. O autor afirma, ainda, que Grube encontrou em Pestalozzi o ponto de partida para suas propostas.

${ }^{3}$ A Revista de Ensino foi um periódico criado pela Associação Beneficente do Professorado de São Paulo, tendo circulado no período 1902-1918. Segundo Catani et. al. (1997, p. 82), nas páginas da revista "é possível acompanhar todas as questões que ocuparam o cenário educacional nos primeiros vinte anos do século, aqui no Brasil. Questões pertinentes à formação e às condições do trabalho docente, salário e carreira, bem como à estruturação das escolas e aos fundamentos das ciências da educação, se fizeram presentes nas produções da Revista de Ensino". 
Rodrigues Alves Pereira, Luiz de Brito compunha uma comissão que assessorou o governo de São Paulo na classificação das obras didáticas com vistas à adoção e compra oficial destes materiais de ensino para a rede escolar paulista. Ao final da relação dos livros e materiais indicados para o ensino de Aritmética, é possível ler no parecer: "O ensino desta matéria deverá começar pelo emprego das Cartas de Parker."4

A partir da oficialização das Cartas de Parker como material fundamental para o ensino de Aritmética, ainda demorou, ao que tudo indica, algum tempo para que este dispositivo didático chegasse às salas de aula, de modo diferente àquele indicado logo ao início de sua divulgação ao professorado, a partir de 1902.

O próximo passo, para além da cópia no quadro negro, foi a materialização das Cartas em forma de gravuras de papel, a serem expostas em cavalete, com o mestre utilizando-as à frente da classe. Assim, de Cartas publicadas em diferentes números da Revista de Ensino nasceram os Mapas, novo nome dado a elas, transformadas em material didático-pedagógico destinado ao uso nas salas de aula. Pode-se conjecturar que, anteriormente à publicação na Revista de Ensino, este dispositivo didático tenha tido circulação restrita como material importado dos Estados Unidos. A partir desta forma original, teriam sido impressas as reproduções feitas no Brasil.

Os arquivos da Editora Melhoramentos indicam a edição do material de Parker a partir de $1909^{5}$. Depois de nove delas, não se tem a informação dos anos em que foram editadas as levas da segunda à nona, foi retomada a publicação somente em janeiro de 1943, com a $10^{a}$ edição dos Mapas de Parker.

A pesquisadora Monalisa Gazoli, consultando a obra 100 anos da Melhoramentos: 1890-1990, escrita por Hernani Donato, informa que a Companhia Melhoramentos de São Paulo (Weiszflog Irmãos Incorporada) resultou da associação, ocorrida em 1920, entre duas empresas distintas: a Companhia Melhoramentos de São Paulo, fundada em 1877, por Antônio Proost Rodovalho, cuja atividade era empreitar obras públicas, tendo sido constituída como fábrica de papel em 1890, e a Weiszflog Irmãos - estabelecimento gráfico fundado em 1906 e cujos proprietários eram os irmãos alemães Otto e Alfried Weiszflog (Gazoli, 2010).

Instalada no Rio de Janeiro no ano de 1890, transferindo-se para São Paulo em 1903, a Editora Melhoramentos incorporou a editora Weiszflog Irmãos no final de 1920. Antes disso, data de 1909 o pioneirismo das publicações na área educacional da Weiszflog. No início, os prelos da Weiszflog Irmãos imprimiam livros da Editora Francisco Alves. De acordo com Soares (2006), isso favoreceu a aproximação posterior da Editora Melhoramentos com o professor Arnaldo de Oliveira Barreto. Este educador-reformador paulista de primeira hora, redator-chefe da Revista de Ensino, compõe um grupo de intelectuais dispostos a elaborar referências para a nova forma construída em São Paulo para o ensino primário: os grupos escolares.

\footnotetext{
${ }^{4}$ Parecer de 27 de fevereiro de 1904, transcrito da página 253 a 262 da Revista de Ensino, n. 2, Ano III, 1904.

${ }^{5}$ Em documento obtido junto à Editora Melhoramentos, o catálogo da empresa mostra que o lançamento dos Mapas de Parker para o ensino da aritmética nas escolas primárias foi feito em 1909. Outra informação importante do documento é que essa publicação teve nove edições (Editora Melhoramentos, 2012).
} 
$\mathrm{Na}$ incorporação da Weiszflog Irmãos, a Melhoramentos, por certo, selecionou as obras que continuou a publicar e, em meio a elas, figuram os Mapas de Parker, conforme consta nos arquivos da Editora. Os mesmos arquivos revelam a publicação deste material até novembro de 1956 e sua comercialização até 1961 (Editora Melhoramentos, 2012). Assim, praticamente durante toda a primeira metade do século 20 , este material foi impresso como referência para o ensino de Aritmética nos anos iniciais escolares.

\section{O material de Parker: de recurso de ensino a modelo pedagógico para o ensino de Aritmética no Brasil}

Com a mudança de materialidade as Cartas transformam-se em Mapas, também, por vezes denominados Quadros, vindo a ganhar maior facilidade de circulação pelos diferentes Estados brasileiros, ávidos em tomar como referência o modelo paulista de instrução primária. Nessa direção, Rosa Fátima de Souza aponta que,

em realidade, o que São Paulo ofereceu às demais regiões brasileiras foi a imagem de um aparelho escolar moderno, articulado, orgânico e bem sucedido. Tal imagem atraiu a atenção das autoridades políticas de outros estados empenhados no ideal republicano de reforma da educação popular. Os expedientes de visibilidade e reconhecimento multiplicaram-se: visitas comissionadas, viagens de estudo, elaboração e publicação de relatórios, circulação de impressos, livros e materiais didáticos. (Souza, 2011, p. 128)

O material didático de Parker, assim, inscreve-se como um dispositivo integrante da estratégia de visibilidade e reconhecimento da política da educação paulista para os anos iniciais escolares. Em específico, tal material ganhou status de condutor de uma metodologia moderna para o ensino do cálculo, denominação de época para os rudimentos aritméticos, praticada em São Paulo, vanguarda da instrução pública nacional.

Uma situação emblemática que mostra a ação dos reformadores paulistas na defesa da organização escolar paulista, de seus métodos, obras e materiais didáticos é a revelada no embate travado entre os professores Arnaldo Barreto e Arthur Thiré. Este debate, relativamente ao ensino de Aritmética no curso primário, está registrado na própria Revista de Ensino. Barreto disputa, nas páginas do periódico, batalha com Arthur Thiré - autor do livro didático Aritmética para principiantes - desqualificando a obra e indicando como deveriam ser escritos os livros didáticos para ensino de Aritmética, em meio ao novo tempo da pedagogia intuitiva. Para tal, Arnaldo Barreto - redator-chefe do periódico - menciona Parker como orientador do ensino de Aritmética e, ainda, enaltece o livro Talks on teaching deste autor. Anos mais adiante, em 1909, Barreto será o responsável pela tradução da obra sob o título Palestras sobre o ensino por Francis Parker ${ }^{6}$.

Assim, tempos depois, a partir das ações de Arnaldo Barreto e suas relações com a Editora Melhoramentos, o material de Parker, em princípio visto como um recurso didático, transformou-se numa referência para o ensino de Matemática, passando a

\footnotetext{
${ }^{6}$ A polêmica Barreto versus Thiré pode ser lida nos seguintes artigos: Arithmetica principiantes, Revista de Ensino em 1902, Ano I, n. 4, p. 762-765; A propósito da arithmetica dos principiantes - I, também em 1902, Ano I, n. 5, p. 976-983; A propósito da arithmetica dos principiantes II, n. 6, p. 1902, Ano I, 1154-1168 e, finalmente, A propósito da arithmetica dos principiantes - apuros do sr. Buarque!, em 1903, Ano II, n. 1, p.
} 45-55. 
constituir um modelo pedagógico a ser utilizado por todos aqueles que acompanham a modernização da pedagogia. Construída esta representação, o material espalhou-se pelo Brasil. Não se trata mais de um recurso para o ensino, trata-se de um modelo pedagógico, de uma metodologia para o ensino intuitivo de Aritmética nos primeiros anos escolares. E será com este status que São Paulo passou a exportar uma nova metodologia para ensino de Aritmética, segundo os ditames do método intuitivo, com o uso do material de Parker.

Um dos primeiros lugares fora de São Paulo a receber o material de Parker foi Santa Catarina. Isso ocorreu em razão da ida para este Estado do professor paulista Orestes Guimarães $^{7}$, contratado pelo governador Vidal Ramos, à vista da excelente repercussão que a reforma do sistema de ensino público paulista teve por todo o país (Teive, 2010). Depois de suas primeiras ações em Santa Catarina, Guimarães elabora o Relatório do Colégio Municipal de 1907 a 1909, apresentado ao Exmo. Sr Superintendente Municipal de Joinville, pelo diretor da comissão - Orestes de Oliveira Guimarães.

Neste relatório Orestes Guimarães realiza um contraponto "entre o que foi a antiga Escola Pública, e o que é o atual Colégio Municipal [...] fundado de acordo com a lei municipal 119 de trinta de janeiro de mil novecentos e sete" (1909, p. 2). Trata-se de mostrar os avanços educacionais do novo, da nova organização escolar, protagonizada pelo próprio Orestes Guimarães. Além disso, o relator já adianta que apesar dos escassos meios materiais, ela atingiu o seu objetivo principal: "fundar em Joinville um estabelecimento de instrução primária integral, em língua do país, seguindo, aproximadamente, os processos adaptados nas escolas de São Paulo" (1909, p. 2).

O relatório segue explicitando os programas de ensino e suas diferentes matérias. No ensino de Aritmética lê-se:

O ensino desta matéria foi também sensivelmente modificado, modificação que começou desde as primeiras classes, pela introdução sistemática de leitura dos quadros de Parker, excelente processo de cálculo mental usado nas escolas de S. Paulo; processo que poupando tempo ao professor, prendendo extraordinariamente atenção de toda a classe, ainda desenvolve muitíssimo as faculdades para os futuros cálculos. No próprio Colégio, já se nota entre seus alunos uma diferença sensível entre as crianças que nas classes superiores praticaram ou não a leitura dos quadros. Posso garantir a Vossa Excelência que todos os senhores professores apreciaram o valor destes quadros pelo que viam de progresso e da atenção dos alunos e hoje manejam com perfeito conhecimento todas as tábuas ou lições do dito quadro. (1909, p. 26)

Em Minas Gerais, por meio do decreto n. 4.508, de 19 de janeiro de 1916, tem-se aprovado o programa do ensino primário do Estado. Para a Aritmética, a ser ministrada no primeiro semestre, a indicação legislativa diz:

\footnotetext{
7 "Paulista de Taubaté, Orestes Guimarães nasceu em 27 de fevereiro de 1871. Ingressou na Escola Normal de São Paulo em 1887, aos dezesteis anos, concluindo-a no ano de 1889. Fez parte, portanto, da primeira geração de normalistas republicanos que, ao longo da Primeira República, alcançou grande prestígio e autoridade intelectual, traduzindo, muito habilmente, as referências consideradas importantes para a regeneração nacional e, consequentemente, para a ordem e o progresso" (Teive, 2010, p. 229). 
Ideia dos valores um, dois, três etc. até nove, contando cousas, os móveis, os alunos, objetos da sala e outros diferentes e bem variados, separandoos pelas qualidades, tamanhos, cores etc. comparando-os pela quantidade, bem como exercitando-os na tábua de Parker e no contador mecânico, ou em figuras no quadro negro até que o aluno distinga com precisão o que é mais e o que é menos e saiba qual o número imediatamente superior e o inferior, na ordem natural da numeração.

Chama a atenção, para o mesmo Estado de Minas Gerais, que o decreto n. 6.753, de $1^{\circ}$ de janeiro de 1925, que aprova os novos programas para do ensino primário mineiro, mantém exatamente o mesmo texto anterior para o ensino inicial da Aritmética no curso primário, onde o material de Parker continua referenciado.

Do mesmo ano de 1916 data o Relatório apresentado ao Exmo. Sr. Dr. Affonso Alves de Camargo - Presidente do Estado do Paraná.- pelo Dr. Enéas Marques dos Santos - Secretário de Estado dos Negócios do Interior, Justiça e Instrução Pública. No que toca à instrução pública, diz o relatório:

Dado o reconhecido adiantamento da instrução pública no Estado de S. Paulo, resolveu o governo enviar àquele importante Estado uma missão de professores normalistas que, generosamente acolhida pelo patriotismo do governo paulista, praticou em grupos escolares durante meses. (...) Adquirida a prática pelos professores da Capital e de outros municípios, poderemos, dentro em pouco tempo, se os resultados assim indicaram, introduzir no Estado, sem grandes despesas e com as devidas cautelas, os métodos que tanto têm elevado o ensino no Estado de S. Paulo. (1916, p. 4-6)

No relatório seguinte, correspondente aos anos de 1917-1918, o mesmo secretário de Estado, ao iniciar o texto sobre a instrução pública, indica que o modelo paulista está fazendo escola no Paraná. Ele observa que

durante o corrente ano prosseguiu esta Secretaria no serviço da reorganização do ensino, não tendo poupado esforços para que no maior número possível das nossas cidades fossem estabelecidos grupos escolares nos moldes do Grupo Modelo, desta Capital, que tanto vem contribuindo para o brilhantismo do ensino público paranaense. (1918, p. 6)

Dois anos após é possível atestar a presença do material de Parker no Paraná: no Relatório apresentado ao Sr. Dr. Secretario Geral de Estado pelo Professor Cesar Prieto Martinez, Inspetor Geral do Ensino lê-se na "relação do material escolar adquirido e encomendado durante o ano de 1920", no item "material para o ensino", "50 Mappas de Parker" (1920, p. 31).

Novamente, na esteira das reformas paulistas para a instrução primária, com a criação dos grupos escolares, outro Estado perfila-se a tomar São Paulo por modelo. Em Sergipe,

o projeto de implantação do modelo dos grupos escolares estava articulado ao discurso da modernização pedagógica e ganhou contornos mais nítidos na voz do médico Helvécio de Andrade, duas vezes diretor da instrução pública: a primeira, no período de 1913 a 1918 e, a segunda, de 1930 a 1935. Helvécio de Andrade representou em Sergipe o entusiasmo 
que contaminou os governos dos demais Estados em face das reformas que se irradiaram a partir de São Paulo. (Carvalho, 2012, p. 214)

Mais especificamente é possível ler a apropriação do modelo paulista, no que se refere ao ensino de Aritmética, em 1917, quando é expedido o Programma para o curso primário nos grupos escolares e escolas isoladas do Estado de Sergipe. Logo à primeira página consta a indicação de que para o ensino primário, o método a ser utilizado é o método objetivo. A seguir seguem-se as instruções gerais para cumprimento deste método. Um de seus itens, o de letra k, a indicação que "toda vez que os alunos levantarem-se ou estiverem desocupados, em torno do quadro negro, da carta de Parker, cruzarão os braços ou conservarão as mãos para trás". Depois das orientações ao professor de como conduzir o ensino da leitura, da higiene e da caligrafia, seguem-se as orientações para o ensino de Aritmética. Dadas passo a passo, na cronologia dos meses letivos, tem-se, para todos eles, o modo de utilizar as Cartas de Parker, no primeiro e segundo anos escolares.

Mais adiante, em 1925, por meio do ato n. 51, do diretor geral do Departamento de Educação do Estado do Rio Grande do Norte, é possível ler, na expedição dos programas e horários dos grupos escolares locais, que para as primeiras classes de Aritmética caberia o ensino das

noções concretas de unidades e quantidades. Contar de 1 a 10 e a 100. Escrita e leitura simultânea de algarismos arábicos. Pequenos rudimentos do cálculo por meio de tornos, cubos, palito ou do contador mecânico. Uso formação e leitura de números por meio de tornos ou palitos, ou riscos no quadro negro; idem, idem, dos signos de somar, diminuir, multiplicar, dividir e igualdade, praticamente. Leitura dos mapas de Parker. Cópia e resolução oral e escrita dos cálculos dos mapas de Parker. Problemas de operações fundamentais.

Santa Catarina, Minas Gerais, Paraná, Sergipe, Rio Grande do Norte e outros Estados brasileiros acolheram o material de Parker. Distribuído pela Editora Melhoramentos, o material fez circular um modelo pedagógico que visava a romper com as formas tradicionais do ensino de Aritmética no curso primário, sobretudo aquela de memorizar a tabuada. Isto representou modernização pedagógica, um modo dos Estados e diretorias da instrução locais mostrarem-se emparelhadas com a vanguarda do ensino encabeçada por São Paulo, pela criação inovadora dos grupos escolares e pela prática do método intuitivo nas classes do curso primário.

\section{A apropriação do material de Parker por Lourenço Filho}

Em 1922 Lourenço Filho chegou à Fortaleza, no Ceará. Com vinte e quatro anos, formado pela Escola Normal de Piracicaba, recém-casado, tornou-se professor de Pedagogia na Escola Normal Pedro II. Aceitou ir de São Paulo para o Ceará, pois estava no começo de sua carreira (Cavalcante, 2009, p. 15).

Os rastros de sua ação em prol da modernização do ensino normal no Ceará nos chegam de modos diversos. Um deles, muito importante, refere-se ao material construído por suas normalistas: 
As lições do jovem Lourenço Filho são copiadas em silêncio, pelas ainda mais jovens, alunas da Escola Normal Pedro II. A forma ordenada com que ele as expõe, permite que as novas ideias sejam facilmente captadas e registradas em cadernos. Serão eles guardados como relíquias e funcionarão, por uma década ou mais, como guias da nova ação pedagógica recomendada para receber os rumores revolucionários da década seguinte. (Bastos; Cavalcante, 2009, p. 11)

Os cadernos com anotações das aulas de Lourenço Filho contemplam todas as rubricas escolares. Ao longo das aulas, tendo sido incentivadas e auxiliadas pelo professor, as normalistas foram elaborando e reelaborando as lições do mestre para, ao final, construírem um livro manuscrito intitulado Álbum com pequenos trabalhos de pedagogia ${ }^{8}$. Um dos capítulos intitula-se Metodologia da aritmética.

Instruções de como usar o material didático-pedagógico - Cartas de Paker, sobretudo - além de tabuinhas, contador mecânico e vários objetos que pudessem ser pesados e medidos constituem a escrita da metodologia da Aritmética anotada pela normalista Maria José Burlamaqui Freire, a partir das aulas de Lourenço Filho. Passo-apasso, lição por lição, o texto mostra dois tipos de diálogo: aquele ouvido pela normalista das aulas de Lourenço Filho e o que deveria ser entabulado entre a professora e seus alunos. É grande o destaque dado às Cartas no capítulo. Ele incluiu instruções de como utilizá-las. Assim, a metodologia da Aritmética levaria em conta que os exercícios da Carta de Parker só deveriam ser passados depois do trabalho da mesma Carta feito pelas crianças oralmente. Apresentada a carta de número 13, por exemplo, seguem as explicações passo-a-passo de como o professor deveria dialogar com o aluno pelo material na obtenção de resultados de contas de somar, subtrair, multiplicar e dividir. A seguir, as anotações mostram a serventia de diferentes cartas:

A carta no. 14 serve para praticarem os alunos sobre adição e subtração, a carta no. 19 serve também para exercícios sobre adição de 1 a 15; a carta 28 serve para exercícios sobre adição e subtração de 1 a 20; as cartas números $31,32,33$ e 34 servem para exercícios sobre adição e subtração de 1 a 100. (Bastos; Cavalcante, 2011)

Lourenço Filho, em termos de novas alternativas para o ensino de Aritmética, segue as orientações vindas das propostas dos republicanos paulistas. É possível dizer que, em tempos de sua estada no Ceará, este professor divulgou o material de Parker e o seu uso. Isso foi notado por Carlos Monarcha ao ponderar que "os alunos dos grupos escolares conheceram o inovador material didático, produzido e vendido ao governo do Ceará pela Companhia Melhoramentos de São Paulo: mapas de Parker, coleções de gravuras para o ensino de linguagem" (Monarcha, 2010, p. 39). Por fim, cabe ressaltar que mesmo sob uma nova denominação - de cartas para mapas - o material utilizado e divulgado por

\footnotetext{
${ }^{8}$ Álbum com pequenos trabalhos de pedagogia são dois cadernos elaborados pelas alunas normalistas com os conteúdos ministrados na cadeira de Psicologia, Pedagogia e Didática, lecionada por Lourenço Filho, durante o ano letivo de 1923. Um caderno é dedicado ao professor Lourenço Filho, no dia 24 de novembro de 1923, na solenidade de formatura, e transcreve o discurso proferido pela normalista Maria José Burlamaqui Freire, que diz: 'Assim é que resolvemos reunir, neste livro, os nossos modestos trabalhos de Pedagogia, porque representam o fructo duma iniciativa vossa e da nossa bôa vontade'. O outro é dedicado ao diretor da Escola Normal Pedro II e professor de Metodologia da Higiene Dr. João Hippolyto de Azevedo e Sá (Bastos; Cavalcante, 2011). 
Lourenço Filho no Ceará foi pouco alterado relativamente ao conteúdo e escrita já editados pela Revista de Ensino a partir de 1902.

A estada de Lourenço Filho no Ceará, em termos do ensino de Aritmética no curso primário, reafirmou o modelo pedagógico que já vinha se espalhando pelo Brasil: o uso das Cartas de Parker.

De volta a São Paulo, em 1924, Lourenço Filho retornou à docência na Escola Normal de Piracicaba, encarregado da disciplina Psicologia. De 1925 a 1930 lecionou Psicologia e Pedagogia na Escola Normal de São Paulo. Com o falecimento de Arnaldo Barreto, Lourenço Filho foi convidado, em 1926, pela editora Weiszflog Irmãos, para dirigir a Biblioteca Infantil, criada em 1915, por Barreto (Soares, 2006). Em 1927 propôs à Editora Melhoramentos de São Paulo a organização de uma série pedagógica, sob o título Biblioteca da Educação. Nesta coleção, que dirigiu até o final de sua vida (1970), publicou e prefaciou obras de educadores brasileiros e estrangeiros (Gandini; Riscal, 1999).

Por certo, a experiência docente de Lourenço Filho com as Cartas/Mapas de Parker, desde os tempos de docência no Ceará, fez com que este professor buscasse, de algum modo, atualizar as orientações de uso deste material didático. Como se disse anteriormente, junto a cada Mapa seguiam textos para os professores. Deste modo, nascem os Mapas para o ensino de Aritmética - Parker - nas escolas primárias reorganizados pelo Prof. Lourenço Filho. Os arquivos da Editora Melhoramentos apontam que este material constitui a $12^{\mathrm{a}}$ edição dos Mapas de Parker (Editora Melhoramentos, 2012). Logo na apresentação do material lê-se:

Os mapas ou quadros de Parker representam, nas escolas primárias de todo o mundo, instrumento habitual para o ensino do cálculo aritmético. Não os dispensam também as nossas escolas, onde o seu uso está generalizado. Nesta nova edição, revista pelo Professor Lourenço Filho, foram feitas várias alterações, tendentes a tornar mais precisos os objetivos de cada série de exercícios, e mais coordenada a sua seriação, bem como foi adotado de modo mais conveniente o emprego dos sinais aritméticos. (Edições Melhoramentos, s/d, p. 2)

Para além de uma atualização no linguajar, Lourenço Filho dirigia-se de forma pessoal aos professores. Fez isso de modo menos diretivo que aquele descrito no material de Parker original. Ao que parece, também, as adaptações de Lourenço Filho reduzem o expediente de uso de coisas para objetivação do ensino de Aritmética.

A esta altura o uso dos Mapas de Parker, referenciado na legislação escolar e mencionado como guia para construção de livros didáticos, identifica-se com a pedagogia nova, da escola ativa, propagada por Lourenço Filho. Os Mapas de Parker, com a assinatura reorganizados pelo Professor Lourenço Filho, passam a ser vistos como se fossem de autoria do próprio Lourenço. Seus desafetos se manifestaram contra as Cartas de Parker, como fez o professor Sud Mennucci, que condenou o uso desse material didático na coluna que assinava no jornal O Estado de São Paulo, do dia 10 de março de 1928. Diz Sud Menucci:

De fato, matemática é a responsável pelo crescente avolumar-se de alunos ignorantes, é o sistema que baseia a aprendizagem numa celebrada "Carta de Parker", grosso "in-folio" cheio de números abolido nas escolas norte- 
americanas, mas de lá, por nós, importado quando a prática já o havia formalmente condenado. (Mennucci, 1928)

De fato, em finais da década de 1920, em termos internacionais, há grande debate sobre o ensino de Aritmética orientado a partir do método intuitivo, sobretudo, em razão dos materiais produzidos a partir desta vaga pedagógica, que tratam o ensino das quatro operações aritméticas de modo simultâneo, como orientado desde há muito por Grube. $\mathrm{E}$ este é o caso do material de Parker. Discute-se que cada operação tem nível diferente de complexidade e, desta forma, é impróprio o ensino considerar as operações conjuntamente.

A pesquisa de Josiane Acácia de Oliveira Marques (2013) inventaria manuais pedagógicos para o ensino de Matemática nos primeiros anos escolares, publicados na década de 1930, que tiveram grande circulação no Brasil. Um destes manuais, mesmo não se configurando propriamente como um manual de Matemática, e sim das diferentes rubricas do ensino primário, contém orientações para o ensino de Aritmética no curso primário. Trata-se da obra Didática da escola nova, de 1935, escrita por Miguel Aguayo.

Relativamente ao método de Grube, Aguayo pondera que

os partidários do método de Grube pretendem que a aprendizagem das operações fundamentais se faça simultaneamente com relação a cada grupo ou número da série de unidades; este processo, porém, não é recomendável. É preferível dividir as dificuldades do cálculo, e ensinar primeiro uma só operação durante certo tempo, depois outra e assim sucessivamente. A prática mais comum é dividir a série numérica em três ou mais partes $(1-10 ; 1-100 ; 1-1000$ etc.). Dentro de cada um destes limites estudam-se uma após outra as operações do cálculo. (Aguayo, 1935, p. 277)

Marques (2013) mostra que o manual de Aguayo teve grande penetração nos meios educacionais brasileiros. Assim, a partir de sua obra, em muitos outros textos, é reproduzida a crítica às propostas de Grube $^{9}$ : trata-se de uma impropriedade didática, que não se coaduna com as recentes pesquisas. Não se deveria misturar o ensino das diferentes operações Aritméticas. As Cartas de Parker constituem dispositivo que propõe um ensino simultâneo das diferentes operações na apresentação de cada número a ser estudado e de suas possíveis formações. Assim, passam, face ao novo ideário pedagógico, a ser consideradas inadequadas.

Não se tem notícia de que Lourenço Filho tenha se pronunciado publicamente na defesa do material de Parker neste contexto de crítica ao modo intuitivo de ensinar Aritmética. De outra parte, como assessor da Editora Melhoramentos, o educador paulista continuou a dar aval à circulação do material, deixando estar seu nome como

\footnotetext{
${ }^{9}$ Dois exemplos podem ser citados a título de ilustração. O primeiro deles reporta ao artigo do diretor do Grupo Escolar Dr. Cardoso de Almeida, da cidade de Botucatu, SP, publicado em 1940, na Revista de Educação, sob o título Didática do cálculo. No texto, o autor faz críticas ao que considera ditos de "consequências imprevisíveis" como: "O exagero do processo de Grube, não admitindo o ensino das operações isoladas e quejandos" (1940, p. 40). Outro exemplo: Irene de Albuquerque, em seu Jogos e recreações matemáticas, afirma: "o alemão Augusto G. Grube, baseado em Pestalozzi, organizou o método monográfico de ensino intuitivo [...] este método é repelido in totum por muitos educadores, não só por se apresentar vinculado a uma exagerada objetivação, como também porque nele as operações fundamentais são ensinadas simultaneamente, como se pudestem ser aprendidas em conjunto e apresentassem o mesmo índice de complexidade" (Albuquerque, 1958, p. 24, $3^{\text {a }}$ edição).
} 
reorganizador deste dispositivo para o ensino de Aritmética e, deste modo, ratificando, com a sua autoridade, a permanência de um modelo já considerado ultrapassado no âmbito internacional das pesquisas sobre o ensino de Aritmética no curso primário.

\section{Considerações finais}

Em meio à dificuldade para traçar linha divisória nítida entre os territórios do ensino intuitivo e da escola ativa, Lourenço Filho foi um dos elaboradores mais incisivos desta distinção. O educador paulista incumbiu-se disto em várias oportunidades, advogando a pedagogia moderna, científica, devedora dos avanços da Psicologia no entendimento de como as crianças aprendem. A escola ativa fez parte de uma nova era estabelecida para o trato das questões educacionais, alicerçadas numa expertise psicológica, que marcou a diferença fundamental das duas vagas pedagógicas. Para trás deveria ficar a pedagogia intuitiva, ainda sob os moldes pré-científicos, ela mesma pouco ou nada informada pelos avanços da psicologia educacional. Lourenço Filho especializou-se nesta matéria de ensino para a formação dos futuros docentes.

Em termos específicos do ensino de Matemática no curso primário, em particular do ensino da Aritmética, a distinção defendida por Lourenço Filho - entre ensino intuitivo e escola ativa - é, por ele mesmo, tornada invisível. A circulação do material de Parker pelo Brasil, com edições até os anos 1960, representou o triunfo de uma representação moderna do ensino de Aritmética calcada nas propostas intuitivas. Com boa aceitação pelos governos estaduais, que incluíam o material no rol das suas compras para equipar as escolas primárias com o que havia de mais moderno, o material ainda ganhou notoriedade com a assinatura de Lourenço Filho, professor considerado um ícone da Escola Nova.

A explicação da continuidade das edições revela uma herança de sucesso de vendas, vinda dos tempos em que São Paulo construiu a imagem de vanguarda do ensino. Se as vendas continuavam, se os governos estaduais continuavam comprando o material, o empreendimento não poderia ser interrompido, mesmo com as inúmeras experiências vindas do Instituto de Educação do Rio de Janeiro, sob a direção de Lourenço Filho a partir de 1932. Lá, professores como Alfredina de Paiva e Souza, da Seção de Prática de Ensino do Instituto, desenvolvia e publicava, no periódico Arquivos do Instituto de Educação, novos modos de ensinar Aritmética, com novas tabuadas que poderiam substituir o material de Parker. Seu trabalho era feito por meio de testes pedagógicos, vindos das práticas consideradas científicas de tratar a Pedagogia, influenciada por recentes pesquisas estadunidenses. Mas isto já é outra história.

\section{Referências}

AGUAYO, Alfredo Miguel. Didática da escola nova. São Paulo: Cia. Editora Nacional, 1935.

ALBUQUERQUE, Irene. Jogos e recreações matemáticas - $1^{\circ}$ volume - $1^{\mathrm{a}}$ e $2^{\mathrm{a}}$ séries. Rio de Janeiro: Conquista, 1958.

BASTOS, Maria Helena Camara; CAVALCANTE, Maria Juraci Maia (orgs.). Álbum com pequenos trabalhos de pedagogia: as normalistas da escola normal do Ceará e a 
pedagogia da escola nova (1923). Santa Maria: Centro Universitário Franciscano, 2011. 1 DVD.

CAVALCANTE, Maria Juraci Maia. Lourenço Filho: do ensino de pedagogia à reforma da instrução pública na terra da literatura (1922-23). In: BASTOS, Maria Helena Camara; CAVALCANTE, Maria Juraci Maia (orgs.). O curso de Lourenço Filho na Escola Normal do Ceará. Campinas: Alínea, 2009, p. 15-36.

BRITO, Joaquim Luís. Cartas de Parker para o ensino de Arithmetica nas escolas primárias. Revista de Ensino. Ano I, n. 1, 1902, p. 3-46.

CATANI, Denice Bárbara; VICENTINI, Paula Perin; LUGLI, Rosário Silvana Genta. O movimento dos professores e a organização da categoria profissional: estudo a partir da Imprensa Periódica Educacional. In: CATANI, Denice Bárbara; BASTOS, Maria Helena Camara (orgs.). Educação em revista: a imprensa periódica e a história da educação. São Paulo: Escrituras, 1997, p. 77-92.

COSTA, David Antonio. A aritmética escolar no ensino primário brasileiro: 1890-1946. Tese (doutorado em Educação Matemática). São Paulo: PUCSP, 2010. 278f. Programa de Pós-Graduação em Educação Matemática, Pontifícia Universidade Católica de São Paulo.

CREMIN, Lawrence. The transformation of the school: progressivism in american education, 1876-1957. New York: Alfred A. Knopf, 1961.

EDIÇÕES MELHORAMENTOS. Mapas para o ensino de Aritmética - Parker - nas escolas primárias - reorganizado pelo Prof. Lourenço Filho, s/d. São Paulo: Arquivo da Editora Melhoramentos. s/d.

GANDINI, Raquel Pereira Chain; RISCAL, Sandra Aparecida. Manoel Bergstrom Lourenço Filho. In: FÁVERO, Maria de Lourdes; BRITO, Jader (orgs.). Dicionário de educadores no Brasil. Rio de Janeiro: UFRJ, 1999.

GAZOLI, Monalisa Renata. O método analítico para o ensino da leitura em Série de Leitura Proença (1926-1928), de Antonio Firmino de Proença. Marília: Unesp, 2010, $209 f$. Dissertação (mestrado em Educação). Programa de Pós-Graduação em Educação.

MARQUES, Josiane Acácia de Oliveira. Manuais pedagógicos e as orientações para o ensino de matemática no curso primário em tempos de escola nova. São Paulo: Unifesp, 2013. 131f. Dissertação (mestrado em Ciências). Programa de Pós-Graduação em Educação e Saúde na Infância e na Adolescência, Universidade Federal de São Paulo.

MENNUCCI, Sud. José Ferraz de Campos - Cálculo dos principiantes - Irmãos Ferraz São Paulo, 1928. Jornal O Estado de São Paulo. 10 mar., 1928.

MINAS GERAIS. Decreto n. 4.508 de 19 de janeiro de 1916. In: SOUZA, Rosa Fátima de (org.). Fontes para o estudo da história da escolar primária no Brasil (1889-1930). Unesp/CNPq, 2011. 1 DVD.

MINAS GERAIS. Decreto n. 6.753 , de $1^{\circ}$ de janeiro de 1925. In: SOUZA, Rosa Fátima (org.). Fontes para o estudo da história da escolar primária no Brasil (1889-1930). Unesp/CNPq, 2011. 1 DVD.

MONARCHA, Carlos Roberto da Silva; LOURENÇO FILHO, Rui. Por Lourenço Filho: uma biobliografia. Brasília: Inep, 2001.

MONTAGUTELLI, Malie. Histoire de l'enseignement aux États-Unis. Paris: Belin, 2000.

NASCIMENTO, Jorge Carvalho. Notas para uma reflexão acerca da escola primária republicana em Sergipe (1889-1930). In: ARAÚJO, José Carlos Souza; SOUZA, Rosa 
Fátima; PINTO, Rúbia-Mar Nunes. Escola primária na primeira república (1889-1930): subsídios para uma história comparada. Araraquara: Junqueira \& Marin, 2012, p. 210-245.

PANIZZOLO, Cláudia. O ensino da leitura pelo método analítico: ideário, práticas pedagógicas e disputas. CONGRESSO BRASILEIRO DE HISTÓRIA DA EDUCAÇÃO, 6 , 2006. Anais ... Goiânia: UFG, 2006.

PARANÁ. Relatório apresentado ao Exmo. Sr. Dr. Affonso Alves de Camargo - Presidente do Estado - pelo Dr. Enéas Marques dos Santos - Secretário de Estado dos Negócios do Interior, Justiça e Instrução Pública, 1916. Disponível em: <https://repositorio.ufsc.br/ handle/123456789/99761>. Acesso em 10 out., 2013.

PARANÁ. Relatório apresentado ao Exmo. Sr. Dr. Affonso Alves de Camargo - Presidente do Estado - pelo Dr. Enéas Marques dos Santos - Secretário de Estado dos Negócios do Interior, Justiça e Instrução Pública, 1918. Disponível em: <https://repositorio.ufsc.br/ handle/123456789/99763>. Acesso em 10 out., 2013.

PARANÁ. Relatório apresentado ao Sr. Dr. Secretario Geral de Estado pelo Professor Cesar Prieto Martinez, Inspetor Geral do Ensino, 1920. Disponível em: $<$ https://repositorio.ufsc.br/handle/123456789/99764>. Acesso em 10 out., 2013.

RIO GRANDE DO NORTE. Diretoria Geral do Departamento de Educação do estado do Rio Grande do Norte Ato no. 51. Expedição dos programas e horários dos grupos escolares, 1925.

SANTA CATARINA. Relatório do Colégio Municipal de 1907 a 1909, apresentado ao Exmo. Sr. Superintendente Municipal de Joinville, pelo diretor da comissão - Orestes de Oliveira Guimarães, 1909. Disponível em: <https://repositorio.ufsc.br/handle/123456789/ 99111>. Acesso em 10 out., 2013.

SERGIPE. Programma para o curso primário nos Grupos Escolares e escolas isoladas do Estado, 1917. Disponível em: <https://repositorio.ufsc.br/handle/123456789/103591>. Acesso em 10 out., de 2013.

SOUZA, Rosa Fátima. Revista de Educação Pública. Cuiabá: UFMT, v. 20, n. 42, 2011, p. 123-143.

TEIVE, Gladys Mary Ghizoni. Sugestões sobre a educação popular no Brasil: proposta do Professor Orestes Guimarães. Currículo sem Fronteiras, v. 10, n. 2, 2010, p. 228-243.

REVISTA DE ENSINO da Associação Beneficente do Professorado Público de São Paulo. São Paulo: Tipografia do Diário Oficial, 1902.

SOARES, Gabriela Pellegrino. Bastidores da edição literária para crianças no Brasil entre os anos 1920 e 1960: a atuação de Lourenço Filho junto à Companhia Melhoramentos. In: DUTRA, Eliana Regina de Freitas; MOLLIER, Jean-Yves (org.). Política, nação e edição: Brasil, Europa e Américas nos séculos XVIII-XX - o lugar dos impressos na construção da vida política. São Paulo: Annablume, 2006, v. 1, p. 513-531.

VALENTE, Wagner Rodrigues. A metodologia da aritmética nas anotações de aulas de Lourenço Filho. In: BASTOS, Maria Helena Camara; CAVALCANTE, Maria Juraci Maia (orgs.). O curso de Lourenço Filho na Escola Normal do Ceará. Campinas: Alínea, 2009, p. 195-206.

VALENTE, Wagner Rodrigues. A matemática na formação do professor do ensino primário: São Paulo (1875-1930). São Paulo: Annablume/Fapesp, 2011. 
VALENTE, Wagner Rodrigues. Lourenço Filho, as Cartas de Parker e as transformações da aritmética escolar. CONGRESSO BRASILEIRO DE HISTÓRIA DA EDUCAÇÃO, 7, 2013, Anais ... Cuiabá: UFMT, 2013.

VALENTE, Wagner Rodrigues. Do ensino ativo para a escola ativa: Lourenço Filho e o material de Parker para a aritmética do curso primário. REUNIÃO NACIONAL DA ANPED, 36, 2013. Anais... Goiânia: UFG, 2013.

WAGNER RODRIGUES VALENTE é professor adjunto livre docente no Departamento de Educação da Escola de Filosofia, Letras e Ciências Humanas da Unifesp, campus Guarulhos. Coordenador do Grupo de Pesquisa de História da Educação Matemática - www.unifesp.br/centros/ghemat.

Endereço: Rua Tiago Ferreira, 57/91 - 11055-140 - Santos - SP - Brasil.

E-mail: wagner.valente@unifesp.br.

Recebido em 10 de maio de 2014.

Aceito em 25 de julho de 2014. 